Viso - Cadernos de estética aplicada Revista eletrônica de estética

ISSN 1981-4062

№ 5, jul-dez/2008

http://www.revistaviso.com.br/
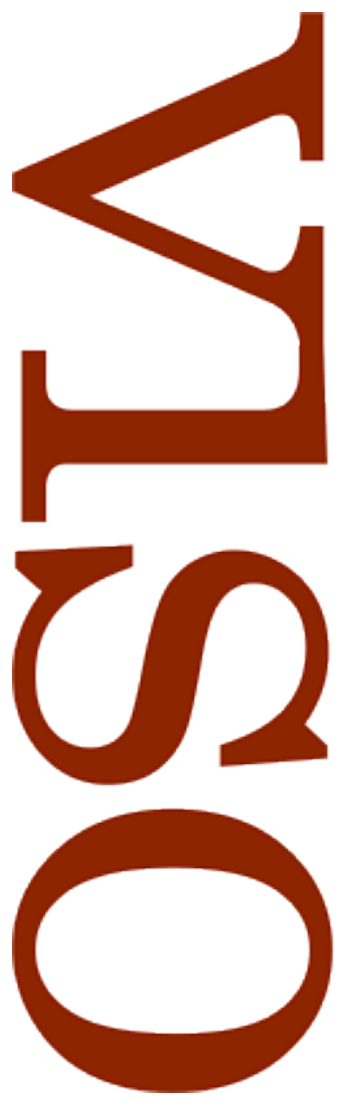

\title{
Sobre a relação entre estética e ética em Rorty e Adorno
} Douglas Garcia Alves Jr. 


\section{RESUMO}

\section{Sobre a relação entre estética e ética em Rorty e Adorno}

Este artigo propõe uma análise das relações entre ética e estética nas obras de Richard Rorty e Theodor W. Adorno. Trata-se de mostrar como os dois autores abordam as origens estéticas e afetivas da moral. A hipótese proposta é a de uma primazia do prático no projeto filosófico de ambos os autores. Um breve comentário de Inteligência artificial> (EUA, 2001), de Steven Spielberg, é esboçado, para ajudar a discernir as diferenças entre as posições filosóficas discutidas, que remetem aos conceitos de "representação do sofrimento" e de "belo" (Rorty) e de "expressão do sofrimento" e de "sublime" (Adorno).

Palavras-chave: ética - filosofia moral - Rorty - Adorno

\section{ABSTRACT}

\section{On the relation between ethics and aesthetics in Rorty and Adorno}

This paper intends to examine the relation between the ethical and the aesthetical in the works of Richard Rorty and Theodor W. Adorno. It aims to show that both authors points out to the aesthetical and affective origins of the moral sphere. A hypothesis is carried out: the primacy of the practical sphere in the philosophical project of both authors. A brief commentary of Spielberg's A.I. (USA, 2001) is drawn in order to help discern the differences between the philosophical positions discussed here, which are based on the concepts of "representation of suffering" and "beautiful" (Rorty), and "expression of suffering" and "sublime" (Adorno).

Keywords: ethics - moral philosophy - Rorty - Adorno 


\section{GARCIA, D. "Sobre a relação entre estética e ética em Rorty e Adorno". In: Viso: Cadernos de estética aplicada, v. II, n. 5 (jul-dez/2008), pp. 40-53.}

DOI: $10.22409 / 1981-4062 / v 5 i / 64$

Aprovado: 30.11.2008. Publicado: 29.12.2008.

(C) 2008 Douglas Garcia Alves Jr. Esse documento é distribuído nos termos da licença Creative Commons Atribuição-NãoComercial 4.0 Internacional (CC-BY-NC), que permite, exceto para fins comerciais, copiar e redistribuir o material em qualquer formato ou meio, bem como remixá-lo, transformá-lo ou criar a partir dele, desde que seja dado o devido crédito e indicada a licença sob a qual ele foi originalmente publicado.

Licença: http://creativecommons.org/licenses/by-nc/4.0/deed.pt_BR

Accepted: 30.11.2008. Published: 29.12.2008.

(C) 2008 Douglas Garcia Alves Jr. This document is distributed under the terms of a Creative Commons Attribution-NonCommercial 4.0 International license (CC-BY-NC) which allows, except for commercial purposes, to copy and redistribute the material in any medium or format and to remix, transform, and build upon the material, provided the original work is properly cited and states its license.

License: http://creativecommons.org/licenses/by-nc/4.0/ 
Em "Inteligência Artificial" (A.I., EUA, 2001), Steven Spielberg ${ }^{1}$ fez uma acurada reflexão a respeito dos laços que unem o estético e o ético. Gostaria de chamar a atenção apenas para dois aspectos dessa complexa relação, que, a meu ver, o filme ajuda a captar.

O primeiro diz respeito ao processo pelo qual David, um andróide criado e programado para substituir o filho de um casal, começa a amar sua "mãe" humana. Ela simplesmente lê para ele um protocolo composto de uma seqüência de palavras. Extraio dessa cena a tese: A relação ética de confiança, cuidado e amor é construída à base de uma cadeia opaca de significantes, irredutível a qualquer configuração cultural. O que torna possível o amor é o aspecto material das palavras, o seu poder mimético, gestual e discernível do significado lingüístico (T1).

O segundo remete à cena em que David, abandonado por sua "mãe" humana, é capturado e levado a uma arena onde são montados espetáculos de destruição ritual de robôs humanóides. A multidão se diverte com os robôs sendo cortados, esmagados e desmembrados, num espetáculo que alude a ressentimento e prazer humanos para com a alteridade inorgânica. Prestes a ser destruído, o pequeno andróide grita e chora. A multidão, comovida, exige que ele seja poupado. Extraio dessa cena a tese: Toda atitude ética de rejeição da crueldade é motivada por uma relação estética de proximidade e identificação com a criatura que sofre, isto é, por uma experiência mimética, e não por raciocínios a partir de princípios abstratos (T2).

O interesse da temática do andróide é que ela permite falar de obrigações morais para com seres criados e programados para satisfazer preferências e demandas humanas. Enquanto preferências dizem respeito ao cumprimento de meios, de funções instrumentais - poderíamos imaginar um robô carregador de objetos, por exemplo demandas podem abranger desejos e laços afetivos. No filme, David é o primeiro andróide programado não só para reagir instrumentalmente a comandos, mas também para engajar-se em laços afetivos. Nesse universo de ficção científica, David seria capaz de ter uma auto-relação afetiva com seu "suporte psicocibernético" e com os seres humanos com quem interage. David teria as propriedades humanas da consciência da autoria das ações e do ser si mesmo dotado de um "corpo". Ao transportar para o andróide as temáticas da filiação, do reconhecimento da autonomia do outro e do sofrimento relativo aos embates com a identidade pessoal, Spielberg agudiza nossas intuições morais a respeito da solidariedade. A questão é: teríamos responsabilidades para com seres artificiais capazes de emoções e de "consciência da dor"? Provavelmente sim.

Não pretendo fazer um comentário do filme de Spielberg em termos estéticos, mas apenas indicar que as grandes questões metafísicas e teológicas que o atravessam - 0 amor, a morte, a linguagem, a relação entre o material e o simbólico, entre ética (solidariedade) e estética (identificação) - conduzem ao centro de uma viva preocupação da filosofia contemporânea: a de como conceber e promover a motivação para agir de 
modo a evitar ou diminuir o sofrimento do "outro", isto é, daqueles que estão, a cada vez, excluídos dos laços mais imediatos de solidariedade presentes na família, nas amizades, nos pequenos grupos profissionais, religiosos, étnicos e nacionais.

Espero tornar plausível a idéia de que Rorty nos ajuda a entender a segunda tese à qual aludi acima, mas não é igualmente capaz de fazê-lo quanto à primeira. Minha hipótese é a de que Adorno nos ajuda a entender melhor os dois aspectos, isto é, as origens prédiscursivas, estéticas, da relação afetiva na base da moral, e os pressupostos da motivação para a solidariedade face ao sofrimento do outro.

Usarei o termo "estético" para me referir ao universo da sensibilidade no seu aspecto duplo, isto é, de receptividade e abertura ao universo múltiplo e contingente das sensações e da imaginação, por um lado, e de relação sensual, de prazer e dor, com a natureza e com o universo simbólico da cultura, por outro. Nesse sentido, o termo "estético" aparece referido ao universo da relação com o particular, o sensível e o contingente, que engloba não só o universo da arte, mas também todo o registro da sensibilidade humana.

\section{Filosofia, estética e ética em Rorty}

Em Contingência, ironia e solidariedade, Rorty deixa claro o caráter de seu projeto filosófico mais abrangente. Esse projeto envolve uma deflação das pretensões normativas da filosofia, por um lado, e a assunção de uma primazia do prático, concebido este como político e retórico, por outro. ${ }^{2}$

Em Rorty, uma filosofia que abandona resolutamente suas pretensões de fundamentação transcendental ou ontológica do âmbito prático deixa-se ver como prática retórica de mediação, engajada na promoção de uma cultura "liberal", uma cultura em que o espaço lógico de descrição do que é o "nós, humanos" pode e deve transformar-se continuamente, incluindo cada vez mais formas de vida e práticas sociais. ${ }^{3} \mathrm{~A}$ rejeição e a diminuição da crueldade são os objetivos dessa prática cultural, que assume sua contingência e a sua ausência de "fundamento" em uma idéia ontológica do "humano". ${ }^{4}$ Uma vez que o "humano" é o que a comunidade define para seus propósitos, incluir cada vez mais exemplares nessa categoria é tarefa maior da política liberal do intelectual filósofo, bem como do romancista, do crítico literário e do antropólogo. Note-se que não é possível ao filósofo pretender qualquer privilégio epistêmico para o desempenho dessa tarefa. Ao contrário, ele é, com freqüência, o menos cotado para desempenhá-la bem, uma vez que não se dirige prioritariamente à imaginação e ao sentimento de identidade dos indivíduos da comunidade. ${ }^{5}$

Nessa perspectiva, "objetividade" ${ }^{6}$ é um nome enganoso, inventado por realistas ingênuos em epistemologia e em ética, perseguidores de uma universalidade independente das práticas humanas. Rorty propõe substituir "objetividade" por 
"solidariedade", isto é, pelo acordo intersubjetivo, sempre limitado, contingente e histórico. O pragmatista concebe o universo epistêmico e moral não como fundado em realidades objetivas independentes, mas como conjunto de práticas cooperativas de construção de crenças, desejos e sentimentos. ${ }^{7}$ Não há como falar de objetividade para além dessas práticas.

O caso paradigmático de Kant, do fugitivo que é perseguido por um assassino, e pede abrigo na casa de alguém ${ }^{8}$, pode ajudar a entender o ponto de Rorty quanto à solidariedade, e seu laço com o estético. Segundo Kant, não se deve mentir ao assassino e dizer que o fugitivo não está em casa. Não se deve, sob nenhuma condição, mentir. Não se trata de conseqüências da ação, trata-se do princípio universal e racional que deve comandar a máxima da ação, se a vontade é a faculdade autônoma de um ser livre que legisla universalmente. Cito Kant:

A veracidade nas declarações, que não se pode evitar, é o dever formal do homem em
relação a quem quer que seja, por maior que seja a desvantagem que daí decorre para
ele ou para outrem; e se não cometo uma injustiça contra quem me força injustamente a
uma declaração, se a falsifico, cometo, pois, mediante tal falsificação, a qual também se
pode chamar mentira (embora não no sentido dos juristas), em geral uma injustiça na
parte mais essencial do Direito: isto é, faço tanto quanto de mim depende que as
declarações em geral não tenham crédito algum, por conseguinte, também que todos os
direitos fundados em contratos sejam abolidos e percam a sua força; o que é uma
injustiça causada à humanidade em geral (A, 304-305). ${ }^{9}$ Segundo Rorty, a filosofia de Kant lida com conceitos morais de um modo não só racional e universalista, mas abstrato, não-contextualista e não-consequencialista. ${ }^{10}$ Nesse sentido, uma concepção transcendental de filosofia vai de par com uma noção transcendental de solidariedade: devemos ser solidários, segundo Kant, não com o indivíduo concreto que sofre diante de nós, ou que está na iminência de sofrer. Não é um sentimento compassivo que deve ditar uma moral genuína, autônoma e imparcial. Só podemos ser morais se fundarmos nossas ações em princípios rigorosamente impessoais, despidos de qualquer sentimentalidade (Kant é um grande crítico da autocomplacência). Só devemos ser solidários com a idéia de uma humanidade racional e autônoma. ${ }^{11}$

Rorty poderia dizer ${ }^{12}$ que, ao condenar incondicionalmente a mentira, e, assim, ao deixar um indivíduo entregue à própria sorte, Kant apela a uma concepção de ser humano, de moralidade e de razão como conceitos objetivos, independentes de quaisquer descrições lingüísticas. ${ }^{13}$ Segundo Rorty, tal tipo de concepção transcendental da moral deveria ser substituído, com maior proveito para uma cultura solidária, por uma concepção empírica e historicista. De acordo com essa concepção, não há propriedades intrinsecamente morais, nem essência humana trans-histórica, nem razão como faculdade privilegiada de acesso a um "real" sobre-humano. 
Contra Kant, segundo Rorty, devemos prestar atenção ao contexto em que vivemos e às conseqüências de nossas ações, se quisermos ser efetivos na promoção de uma comunidade mais inclusiva e mais democrática, na qual os apelos à crueldade contra os "diferentes" possam aparecer como absurdos e inaceitáveis. Apelando ao vocabulário de Michael Walzer ${ }^{14}$, Rorty ancora a moral num tipo de sensibilidade, naquilo que em nossa experiência é "caudaloso", no sentido de efetivamente mobilizador para a ação. Identificar a moral com a razão, como fez Kant, seria um erro, pois ela nada mais é do que o "ralo" em nossa experiência, aquilo que permite articular princípios gerais, os quais são sempre problemáticos, e sujeitos à revisão, pressionados pelo veio "caudaloso" da nossa complexa experiência social. ${ }^{15}$

Se a moral é questão de sensibilidade, contingente, limitada, situada, e não de razão prática, necessária, transcendental, universal, o aspecto estético ganha uma importância central para a ética e a política de Rorty. Trata-se de imaginar, de descrever, de narrar o sofrimento do(s) "outro(s)" para que ele se torne menos "estranho" a nós. Ao ver diminuir imaginativamente a distância entre o sofrimento e a história de vida de pessoas situadas bem longe de nosso espectro de identidade cultural e moral, tornamo-nos mais sensíveis à sua identidade moral e às implicações potencialmente cruéis de nossas ações, e às do Estado que nos representa. ${ }^{16}$

Conquanto Rorty não tenha deixado indicações claras a respeito, podemos nos perguntar: como seria uma estética rortiana? Minha hipótese é de que essa estética seria próxima de uma estética do belo, ou talvez, mais do que isso, da busca da "boa forma", daquilo que projeta uma reconciliação possível a partir das fraturas da situação histórica. O impulso profundamente utópico - no sentido liberal ${ }^{17}$ - de seu pensamento, ainda que retire da história qualquer aspecto de teleologia, faz ancorar na imaginação narrativa e na retórica pública os anseios de uma síntese do múltiplo, do conflituoso e da esfera material, na comunidade de falantes que, no final das contas, resolve o seu vocabulário comum em acordos, ainda que instáveis. $\mathrm{O}$ artista idealizado por Rorty é uma espécie de herói da cultura, ele dá voz às vítimas torturadas e aos excluídos, que não são capazes de fazê-lo em primeira pessoa. ${ }^{18}$

Em um escrito sobre a natureza do trabalho filosófico, Rorty emprega categorias estéticas ${ }^{19}$ para propor uma distinção metafilosófica: belo e sublime podem funcionar como senhas para concepções de filosofia que privilegiam a investigação do condicionado, ou a busca do incondicionado. A busca do belo, em filosofia, seria a tentativa de integração dos conhecimentos assumidos como racionais em sínteses elegantes e harmoniosas, enquanto a do sublime seria a tentativa de entrar em contato com algo de inefável, algo "objetivo" e "real", que escaparia ao discursivo, "algo que não admite re-descrição, nem re-contextualização". ${ }^{20}$ Segundo Rorty, as filosofias "sublimes" se "afastam das práticas sociais e das normas que estabelecem o que se considera uma discussão racional". ${ }^{21}$ Essa tipologia não se aplicaria imediatamente ao recorte "analíticos" e "continentais", mas à distinção entre aqueles que buscam consenso e 
aqueles que buscam correspondência com o "mundo" (Habermas versus Heidegger, Davidson versus McDowell). O primeiro tipo de filosofia (que busca o "belo" e a "coerência") poderia ser caracterizado pela aceitação de uma imanência lingüística no cerne de todo conhecimento, enquanto que o segundo tipo de filosofia (que busca o "sublime" e a "correspondência") se definiria pela busca de uma verdade não-lingüística, de um "real" literal, destacado de toda "representação". A implicação ética e política dessas diferentes concepções do trabalho filosófico far-se-ia sentir, segundo Rorty, na idéia de que buscar o belo em matéria de práxis social significa aceitar a contingência e a falibilidade de consensos que se propõem a regular melhor as interações humanas já existentes; por outro lado, a busca de sublimidade na ética e na política implicaria uma aspiração por uma humanidade e um tipo de instituições radicalmente outros em relação a tudo que existe: uma aspiração por um novo homem e uma nova política. Para os adeptos do belo, a aspiração seria "mais igualdade, menos sofrimento" (algo relativo), enquanto que para os perseguidores do sublime, a busca seria por "liberdade absoluta, autonomia plena, um mundo em que não seriam necessários compromissos entre interesses em conflito"22, isto é, a realização do "equivalente moral da correspondência com a estrutura intrínseca da realidade" - algo absoluto. Note-se que Rorty reputa ao "sublime" político a indiferença quanto ao compromisso de interesses, e a ilusão da superação total da necessidade. Ao "belo" político, por outro lado, Rorty reputa uma sábia adaptabilidade à evolução cultural da espécie humana. Do lado do belo, ter-se-ia a busca dialógica pelo razoável, a conversação, o discursivo; do lado do sublime, a busca não-dialógica pelo incondicionado, a conversão, o não-discursivo.

Como entender essa distinção rortiana entre belo e sublime em relação às duas teses que apresentei no início? Quanto à segunda tese, a de um laço entre ética anti-crueldade e estética da identificação mimética, não há problemas: a defesa rortiana de uma filosofia que busca o belo, entendido este como acordo de vocabulários e práticas sociais, concilia-se bem com essa tese. As coisas se passam diferentemente com relação à primeira tese, que remete a ética a uma relação afetiva de base, irredutível ao consenso lingüístico (ao plano das significações estabelecidas culturalmente). Rorty veria um traço de sublimidade suspeita nessa tese, um aspecto romântico de busca do incondicionado, do inefável, de um "realismo" na esfera da moral.

No que se segue, apresento uma perspectiva diversa, a de Theodor Adorno, que permite, a meu ver, pensar o sublime (e sua relação com a ética) de uma outra maneira.

\section{Filosofia estética e ética em Adorno}

Em Adorno, há também uma nítida primazia do prático em seu projeto filosófico, ainda que esta assuma contornos distintos do caso de Rorty. Nos termos da Dialética Negativa, trata-se de trazer à consciência esclarecida a cumplicidade da filosofia com a dominação da natureza e com a desvalorização do não-idêntico, somático, individual e histórico. 
Esse impulso de crítica da metafísica e revalorização do contingente converge com o sentido da crítica metafilosófica de Rorty, ainda que a partir de outras bases. ${ }^{23}$

Espero poder indicar quais são essas bases: em Adorno, a filosofia não abandona suas pretensões normativas, mas tensiona ao máximo suas próprias posições de sentido. Diferentemente de Rorty, Adorno não abandona um conceito forte de razão, mas o resitua a partir da natureza e do somático. Desse modo, a idéia de que a razão é natureza transformada, de que há um somatismo imanente ao espírito, conduz a filosofia a uma exigência de constante auto-reflexão a respeito de toda posição de universalidade normativa, contra sua absolutização. ${ }^{24}$

Em um de seus cursos na Universidade de Frankfurt, Problemas de filosofia moral (1963), Adorno usa uma analogia para esclarecer a ambigüidade do universal e da ordem normativa: poder-se-ia pensar, à primeira vista, que o drogado é o mais livre dos seres, uma vez que suas produções psíquicas não estão subsumidas ao registro de uma eticidade social, nem aos códigos imaginários vigentes sobre beleza, prazer, poder, corporeidade etc. Mas não é isso que se passa, afirma Adorno. O drogado, cujas produções psíquicas não se submetem a esse tipo de ordem do princípio do ajuste social, é, na verdade, submetido violentamente a correntes psíquicas sobre as quais não possui nenhum controle. A ligação a uma ordem da eticidade social é condição necessária para a assunção do autocontrole, condição da autonomia. Isso não equivale, continua Adorno, a absolutizar a ordem constituída, com se ela fosse a fonte única de todo sentido moral. ${ }^{25}$

Nesse mesmo curso, Adorno propõe a idéia de que a principal tarefa da investigação filosófica sobre a moral é a de sempre fazer uma reflexão sobre as complexas relações entre a eticidade social que é sempre repressora, mas, ao mesmo tempo, condição de autonomia do sujeito (isto é, o pólo universal da filosofia moral), e, por outro lado, o aspecto vulnerável à dor do ser humano individual (o pólo singular da filosofia moral). ${ }^{26}$

Segundo Adorno, não há uma moral objetiva, em termos de uma ordenação eterna da moral. Há uma intersubjetividade primeira, corpórea, pré-subjetiva, pré-discursiva: ela existe no nível de uma disposição mimética originária, que encerra os seres humanos em um espaço comum de experiência a partir do qual a moralidade pode ser construída. ${ }^{27}$

Dizer que não há uma moral objetiva, em termos ontológicos, não significa dizer que a moral não tem um aspecto objetivo para os sujeitos humanos. Voltemos ao caso paradigmático de Kant, do fugitivo que é perseguido por um assassino, e pede abrigo na casa de alguém. A leitura de Adorno sobre o encaminhamento kantiano tem muito em comum, nos resultados, com as críticas levantadas por Rorty: é inadmissível tal grau de abstração do raciocínio moral, que leva à desconsideração das conseqüências da ação para o sofrimento do sujeito individual. ${ }^{28} \mathrm{Em}$ Adorno, contudo, o caso de Kant leva a pensar em um aspecto objetivo na raiz da moral: trata-se do impulso, algo que Adorno 
afirma que é da ordem do "não-subjetivo no sujeito", do não-referenciável a razões ou escrutínios morais. Cito a Dialética Negativa:

Com o empenho por uma racionalização implacável, seriam renegados o impulso, a ansiedade nuamente física e o sentimento de solidariedade para com os, nos dizeres de Brecht, corpos torturáveis - que são imanentes às ações morais. O mais urgente tornarse-ia outra vez algo contemplativo, em escárnio da própria urgência. A diferença entre teoria e práxis implica, no plano da teoria, que a práxis não pode resolver-se sem resto na teoria, nem que é sua Xwpıs. Ambas não se deixam reduzir a uma síntese..$^{29}$

O impulso não pode ser hipostasiado como um fundamento ontológico, nem como primeiro princípio da moral. Ele indica um limite da razão universalista na esfera da moral. Isso não significa que a universalidade normativa seja uma farsa ou algo sem sentido, mas, diversamente, trata-se de indicar que ela tem seu limite na realidade objetiva da imanência corpórea e vulnerável do indivíduo. Assim, possuem a mesma dignidade, em termos de resistência à crueldade, as razões universalistas para a ação moral e o sentimento bruto, a reação impulsiva diante do sofrimento de um indivíduo prestes a ser torturado. Poder-se-ia dizer que razão e impulso são momentos que se desdobram na mediação do fenômeno moral. ${ }^{30}$

Abro um parêntese: Habermas, depois das críticas endereçadas a Adorno ${ }^{31}$, parece aproximar-se, mais recentemente, de posições adornianas, na medida em que admite uma pré-condição subjetiva do agir comunicativo, condição esta que se refere à relação do sujeito moral com seu corpo próprio. Cito Habermas, em O futuro da natureza humana:

Certamente, a pessoa só consegue se ver como autor de ações imputáveis e como
fonte de pretensões autênticas se supuser a continuidade de um si mesmo, que
permanece idêntico a si mesmo ao longo da história de vida. Sem essa suposição, não
poderíamos encontrar nosso destino determinado pela socialização de maneira refletida,
nem formar uma autocompreensão revisória... O 'si mesmo' de uma pessoa que fosse
exclusivamente o produto de um destino determinado e imposto apenas pela
socialização escaparia na corrente de constelações, relaçães e relevâncias atuantes em
sua formação. Na mudança da história de vida, a continuação do ser si mesmo só é
possível porque podemos vincular a diferença entre o que somos e o que nos ocorre a
uma existência corporal que é o prosseguimento de um destino natural subjacente ao
processo de socialização (p. $82 f){ }^{32}$

Seria interessante investigar, no arcabouço da teoria moral habermasiana, como se constitui e se desenvolve essa apreciação crítica do eu, ligado a um corpo que é atravessado por afetos. Isso seria assunto para um outro trabalho, que abordaria as relações entre o ético e o estético em Habermas. Por ora, interessa-me indicar o modo como a estética é importante para Adorno pensar a moral: trata-se de indicar a primazia de uma experiência do não-idêntico, pré-discursiva, de uma dependência do subjetivo em relação ao material, e do lingüístico em relação ao somático. A partir daí, penso que a categoria estética central para a questão da solidariedade em Adorno não seria a de 
representação do sofrimento, como em Rorty, mas a de expressão do sofrimento ${ }^{33}$, que daria lugar a uma estética do sublime. $\mathrm{O}$ artista - e o filósofo - não seria mais visto como o herói da cultura, e sim como o representante de sua condição trágica.

Eu disse anteriormente que há, em Adorno, a idéia de uma intersubjetividade primeira, de caráter pré-lingüístico, a qual, em última análise, nos remeteria a uma proximidade afetiva e moral até mesmo com o animal, na medida em que este pode ser pensado como portador de uma espécie incipiente de subjetividade, própria de um ser capaz de sentir dor e de opor resistência a ela. O modo pelo qual a estética e a moral se relacionam, em Adorno, centra-se na sua interpretação do sublime. Como aponta Márcio Seligmann-Silva, Adorno "assumiu como um dos desideratos de sua teoria estética fornecer os fundamentos de uma obra de arte que possa apresentar este indivíduo totalmente abandonado ao sofrimento" ${ }^{34}$, como um animal, posto nos extremos da tortura e da desintegração psíquica. O artista contemporâneo, visado por Adorno, não é o herói rortiano, mas, continuo citando Seligmann-Silva, alguém que "descortina o pré e o póssimbólico. O limite dessa pesquisa é posto pela própria questão das bordas entre arte e natureza, a saber, entre a noção de humanidade e de animalidade". ${ }^{35}$

Nesse sentido, para Adorno, a questão não é a de representar o sofrimento, de dar uma voz substituta àqueles que não têm voz, como propõe Rorty. A estética da expressão do sofrimento, em Adorno, não diz respeito à mera expressão psicológica de emoções dolorosas. A expressão do sofrimento na arte - e na filosofia - possui um significado político fundamental: passamos de uma estética vinculada a uma política do reconhecimento das diferenças no horizonte comum de práticas conversacionais - isto é, uma estética da representação - para uma estética do não-referenciável, para uma estética - e uma política - da expressão do que não tem lugar, do que se afirma negando, do limite das pretensões universalizantes e conciliatórias do jogo político.

Adorno nos remete à exigência de uma estética que não é engajada no plano conteudístico, de uma arte que busca uma expressão política no plano formal, por meio da elaboração não violenta do elemento particular e natural. Essa arte é "espiritualização" [Vergeistigung] do sensível, no sentido de que recorda a imanência natural da razão e o aspecto contingente e sofredor do humano. É nesse sentido preciso que a arte contemporânea, para Adorno, é uma arte do sublime. Cito duas passagens muito próximas da Teoria Estética:

A teoria kantiana do sublime antecipa no belo natural aquela espiritualização que só a arte realiza. O que na natureza é sublime é nele apenas a autonomia do espírito perante a preponderância do ente sensível e ela só se consuma na obra de arte espiritualizada. ${ }^{36}$

E, mais adiante:

O primado do espírito na arte e a introdução do que antes era tabu são dois lados do mesmo estado de coisas. Aplica-se ao que a sociedade já não aprova e pré-forma e 
transforma-se assim numa relação social de negação determinada. A espiritualização não se realiza mediante ideais que a arte manifesta, mas através da força com que ela penetra nos estratos não-intencionais e avessos às idéias. Este não é o menor dos motivos pelos quais o proscrito e o proibido atraem o ingenium artístico. A arte nova, por meio da espiritualização, evita - como o deseja a cultura limitada - se deixar sujar pelo verdadeiro, pelo belo e pelo bem. O que se costuma chamar de crítica social ou engajamento da arte, o seu aspecto crítico ou negativo, é até as suas células mais íntimas unido ao espírito, sua lei formal. ${ }^{37}$

Para concluir, encerro com a posição de três questões que retomam e desdobram o percurso aqui proposto. Em primeiro lugar, a arte que aspira mobilizar nossa capacidade para a solidariedade e para a consideração dos excluídos da sociedade alcança mais quando se faz descrição de histórias de sofrimento, num empenho moral? A filosofia que se quer lugar-tenente de uma práxis mais justa pode prescindir do contato com os potenciais reflexivos liberados pela arte? A localização da moralidade na esfera do racional, sem considerar a noção de sensibilidade estética para com o "proscrito e o proibido", seria capaz de dar conta da relação dos seres humanos com a natureza?

\section{* Douglas Garcia Alves Júnior é professor do Departamento de Filosofia da UFOP.}

${ }^{1}$ A. I. é um caso de autoria coletiva: o conto de Brian Aldiss, "Superbrinquedos duram o verão todo" foi a base para Stanley Kubrick imaginar o filme. Ele trabalhou no roteiro do filme por muitos anos, no início com Aldiss, e depois com Spielberg. Com a morte de Kubrick, Spielberg assume o projeto de levar o filme às telas e dá a forma final ao roteiro. Cf. o conto que inspirou o filme: ALDISS, B. Superbrinquedos duram o verão todo e outros contos de um tempo futuro. Trad. de Beth Vieira. São Paulo: Companhia das Letras, 2001.

${ }^{2}$ RORTY, R. Contingência, ironia e solidariedade. Trad. de Nuno Ferreira da Fonseca. Lisboa: Editorial Presença, 1994. Cf. especialmente, a esse respeito, os capítulos "A contingência de uma comunidade liberal" e "Ironia privada e esperança liberal".

${ }^{3}$ Idem, pp. 236-239.

${ }^{4}$ Idem, pp. 100; 235; 241; 244ff. Cf. também, a esse respeito: RORTY, R. "Direitos humanos, racionalidade e sentimentalidade". In: Verdade e progresso. Trad. de Denise Sales. Barueri: Manole, 2005 (especialmente pp. 202ff).

${ }^{5}$ Cf. RORTY, R. Contingência, ironia e solidariedade, op. cit., pp. 112; 124-128; 244.

${ }^{6}$ Cf. RORTY, R. "Solidariedade ou objetividade?" In: Objetivismo, relativismo e verdade. Trad. de Marco Antônio Casanova. Rio de Janeiro: Relume-Dumará, 2002.

${ }^{7}$ Cf. Ibidem, pp. 39; 46-48. Cf. também "Direitos humanos, racionalidade e sentimentalidade", op. cit., pp. 204ff, bem como Contingência, ironia e solidariedade, op. cit., pp. 99ff; 211; 217.

${ }^{8}$ KANT, I. "Sobre um suposto direito de mentir por amor à humanidade". In: A paz perpétua e outros opúsculos. Trad. de Artur Morão. Lisboa: Edições 70, 1995.

${ }^{9}$ Idem, pp. $174 \mathrm{ff}$.

${ }^{10}$ Cf. a avaliação que Rorty faz de Kant em "Direitos humanos, racionalidade e sentimentalidade", op. cit., pp. $213 ; 219 \mathrm{ff}$. 
${ }^{11}$ Cf. KANT, I. Crítica da razão prática. Tradução de Artur Morão. Lisboa: Edições 70, 1994. Cf. especialmente o capítulo III da "Analítica da razão pura prática", "Dos motivos da razão pura prática", onde se lê: "é muito belo fazer bem aos homens por amor e benevolência simpática [...], no entanto, essa não é a autêntica máxima moral de nossa conduta, adequada à nossa situação moral enquanto homens" (A 146).

12 Rorty não comenta diretamente o escrito kantiano sobre a mentira, mas toda a sua linha de argumentação crítica a Kant é condizente, a meu ver, com a perspectiva que apresento aqui. Cf. especialmente: RORTY, R. "Justiça como lealdade ampliada". In: Pragmatismo e política. Trad. de Paulo Ghiraldelli Jr. São Paulo: Martins Fontes, 2005, pp. 101-122.

${ }^{13}$ Conforme os argumentos de Rorty em Contingência, Ironia e solidariedade, op. cit., pp. 217; 235; 239; 241.

${ }^{14}$ Cf. Rorty, Justiça como lealdade ampliada, op. cit., pp. 105ff. Rorty refere-se a: WALZER, M. Thick and thin: moral arguments at home and abroad. Notre Dame: Notre Dame University, 1994.

${ }^{15}$ Nesse sentido, segundo Rorty, "a lei moral é, na melhor das hipóteses, uma abreviação cômoda para uma rede concreta de práticas sociais" (Justiça como lealdade ampliada, op. cit., p. 109).

${ }^{16}$ Cf. RORTY, R. Contingência, Ironia e solidariedade, op. cit., pp. 112; 125-128; 236.

${ }^{17}$ Cf. a defesa da idéia de uma "utopia liberal" em RORTY, R. Contingência, Ironia e solidariedade, op. cit., pp. 72-74; 90; 99f. Trata-se de um ideal regulador da esfera política, contingente e falível, como afirma Rorty, na Introdução do livro, p. 18: "Na minha utopia, a solidariedade humana seria vista não como um fato que haveria apenas que reconhecer uma vez removidos os 'preconceitos' ou alcançadas profundezas até então ocultas, mas sim como um objetivo a atingir. Um objetivo a atingir não pela investigação, mas sim pela imaginação, pela capacidade imaginativa de ver em pessoas estranhas companheiros de sofrimento. A solidariedade não é descoberta pela reflexão, mas sim criada. É criada com o aumento de nossa sensibilidade aos pormenores específicos da dor e da humilhação de outros tipos, não familiares, de pessoas".

${ }^{18}$ Cf. RORTY, R. Contingência, Ironia e solidariedade, op. cit., onde ele afirma que o artista deve fornecer à cultura liberal "descrições pormenorizadas de variedades particulares de dor e humilhação" (p. 239), uma vez que "as vítimas da crueldade, as pessoas que sofrem não têm muito a ver com uma linguagem. É por isso que não há uma 'voz dos oprimidos' ou uma 'linguagem das vítimas'. A linguagem que em tempos as vítimas usaram já não funciona e essas vítimas estão a sofrer demasiadamente para coordenar novas palavras. Assim, o trabalho de pôr a sua situação numa linguagem terá de ser feito por alguém em seu lugar. O romancista, poeta ou jornalista liberal desempenha bem essa função. Regra geral, o teórico liberal não" (p. 127).

${ }^{19}$ Cf. RORTY, R. "La belleza racional, lo sublime no discursivo y la comunidad de filósofas y filósofos". In: Logos. Anales del Seminario de Metafísica. Madri, vol. 34, 2001, pp. 45-65. Agradeço a Ricardo Barbosa a gentileza de ter chamado minha atenção para este artigo. Trata-se, segundo Rorty, de uma tipologia de cunho histórico e hermenêutico, restrita ao último século, e aos departamentos de filosofia no Ocidente.

20 Ibidem, p. 50.

${ }^{21}$ Ibidem, p. 54.

22 Ibidem, p. 61.

${ }^{23}$ Para um tratamento extenso do lugar dessas questões no pensamento mais global de Adorno, remeto o leitor ao meu Dialética da vertigem: Adorno e a filosofia moral. São Paulo/Belo Horizonte: Escuta/FUMEC, 2005.

${ }^{24}$ Cf. SCHWEPPENHÄUSER, G. "A filosofia moral negativa de Theodor W. Adorno". In: Educação e Sociedade, v. 24, n. 83, Campinas, 2003, pp. 391-415. 
${ }^{25}$ Cf. ADORNO, T. Probleme der Moralphilosophie. Editado por Thomas Schröder. Frankfurt am Main: Suhrkamp, 1997, p. 181

${ }^{26}$ Ibidem, pp. 15f; 23; 29; 34.

${ }^{27}$ Cf. a esse respeito especialmente as seções "Passagem ao materialismo" [Übergang zum Materialismus], "Sobre o conceito de espírito" [Zum Begriff des Geistes] e "O sofrimento é físico" [Leid physisch], da Dialética Negativa, in: ADORNO, T. Negative Dialektik, Gesammelte Schriften, v. 6. Frankurt am Main: Suhrkamp, 1970, pp. 193; 198f; 202f. Para um comentário destes textos, remeto o leitor ao meu Dialética da vertigem, pp. 271-291.

${ }^{28}$ Cf. ADORO, T. Probleme der Moralphilosophie, op. cit., pp. $144 \mathrm{f}$.

${ }^{29}$ A tradução é de minha autoria. No original: "Der Impuls, die nackte physische Angst und das Gefühl der Solidarität mit den, nach Brechts Wort, quälbaren Körpern, der dem moralischen Verhalten immanent ist, würde durchs Bestreben rücksichtsloser Rationalisierung verleugnet; das Dringlichste würde abermals kontemplativ, Spott auf die eigene Dringlichkeit. Der Unterschied von Theorie und Praxis involviert theoretisch, daß Praxis so wenig rein auf Theorie zu bringen ist wie Xwpıৎ von ihr. Beides läßt nicht zur Synthese sich zusammenleimen“. ADORO, T. Negative Dialektik, op. cit., pp. $281 \mathrm{f}$.

${ }^{30}$ É o que Adorno chama de (insolúvel) "dialética moral" [moralischer Dialektik]. Cf. ADORNO, T. Probleme der Moraphilosophie, op. cit., pp. 144f; $234 \mathrm{f}$.

${ }^{31}$ Notadamente em seu O discurso filosófico da modernidade. São Paulo: Martins Fontes, 2002, pp. 153-186.

32 HABERMAS, J. O futuro da natureza humana: a caminho de uma eugenia liberal? São Paulo: Martins Fontes, 2004. Cf. também pp. 65f; 80.

${ }^{33}$ Cf., numa perspectiva próxima à minha, os trabalhos de Rodrigo Duarte sobre o conceito de expressão em Adorno, reunidos no livro Dizer o que não se deixa dizer: para uma filosofia da expressão. Chapecó: Editora Argos, 2008.

34 SELIGMANN-SILVA, M. "Paisagens da arte contemporânea. Documenta 11 de 2002 e Nova York 11/09/2001". In: PESSOA, F. (org.) Arte no pensamento: Seminários Internacionais Museu Vale do Rio Doce 2006. Vitória: Museu Vale do Rio Doce, 2006, p. 301.

${ }^{35}$ Ibidem, p. 298.

${ }^{36}$ ADORNO, T. Teoria Estética. Trad. de Artur Morão. Lisboa: Edições 70, 1993, p. 111 (tradução ligeiramente modificada). No original: "Kants Theorie des Erhabenen antezipiert am Naturschönen jene Vergeistigung, die Kunst erst leistet. Was an der Natur erhaben sei, ist bei ihm nichts anderes als eben die Autonomie des Geistes angesichts der Übermacht des sinnlichen Daseins, und sie setzt erst im vergeistigten Kunstwerk sich durch." (Ästhetische Theorie, Gesammelte Schriften, v. 7. Frankurt am Main: Suhrkamp, 1970, p. 143.)

${ }^{37}$ Ibidem, p. 112 (tradução modificada). No original: „Der Primat des Geistes in der Kunst und das Eindringen des zuvor Tabuierten sind zwei Seiten des gleichen Sachverhalts. Er gilt dem nicht bereits gesellschaftlich Approbierten und Vorgeformten und wird dadurch zu einem gesellschaftlichen Verhältnis bestimmter Negation. Vergeistigung vollzieht sich nicht durch Ideen, welche die Kunst bekundet, sondern durch die Kraft, mit der sie intentionslose und ideenfeindliche Schichten durchdringt. Nicht zuletzt darum lockt das Verfemte und Verbotene das künstlerische Ingenium. Die neue Kunst von Vergeistigung verhindert, wie die banausische Kultur es will, mit dem Wahren, Schönen und Guten weiter sich zu beflecken. Bis in ihre innersten Zellen ist, was man an der Kunst gesellschaftliche Kritik oder Engagement zu nennen pflegt, ihr Kritisches oder Negatives, mit dem Geist, ihrem Formgesetz zusammengewachsen.“ (p. 144f) 